\title{
Evaluation of the ISUS Power Management and Pistribution System Under Operational Conditions
}

\author{
S. \\ S. Michael Luker' ${ }^{1}$, F. J. Wyant ${ }^{2}$, MAJ R. C. Nelson ${ }^{3}$, Robert M. Button ${ }^{4}$ \\ 'Sandia National Laboratories, P. O. Box 5800, Albuquerque, NM 87185; (505) 845-8886, smluke@ (ándia.gov \\ ${ }^{2}$ Sandia National Laboratories, P. O. Box 5800, Albuquerque, NM 87185; (505) 846-8889, fjwyant@sandia.gov \\ ${ }^{3}$ Field Command Defense Special Weapons Agency, 1680 Texas St. SE, Kirtland AFB, NM 87117 \\ ${ }^{4}$ National Aeronautics and Space Administration, Lewis Research Center, 21000 Brookpark Rd., Cleveland, Ohio \\ 44135; (216) 433-8010, Robert.M.Button@lerc.nasa.gov
}

\begin{abstract}
An operational evaluation of the Integrated Solar Upper Stage (ISUS) power management and distribution (PMAD) system was conducted as part of the Engine Ground Demonstration thermionic power system test program-START-3. START-3 testing took place at the Baikal Test Stand, located in the University of New Mexico's Energy Conversion Research Laboratory at the New Mexico Engineering Research Institute in Albuquerque, NM. One objective of this test was to evaluate the operational performance of the ISUS PMAD system developed by the National Aeronautics and Space Administration (NASA) Lewis Research Center. Tests of the PMAD with the ISUS diode string demonstrated that the PMAD could regulate the output of an array of thermionic converters within the design requirements and could be modified to optimize performance for diode strings of fewer than 16 diodes.
\end{abstract}

\section{INTRODUCTION}

An operational demonstration and performance characterization test of sixteen prototype thermionic converters was undertaken in mid-1998 as part of the Air Force Research Laboratory (formerly Phillips Laboratory)-sponsored Integrated Solar Upper Stage (ISUS) development program. The START-3 test took place at the Baikal Test Stand, located at the University of New Mexico's Energy Conversion Research Lab at the New Mexico Engineering Research Institute (NMERI) in Albuquerque, NM. This assessment test was also supported by the Defense Special Weapons Agency as part of their Advanced Thermionics Program. This test was a follow-on test to the Engine Ground Demonstration (EGD) test conducted in 1997 at the NASA Lewis Research Center, where the performance capability of the propulsion unit was investigated (Kudija, 1998).

The principal objective of the START-3 test was to demonstrate and characterize the operational performance of the ISUS EGD thermionic power system at several emitter temperatures. A secondary objective of the test was to evaluate the operational performance of the ISUS power management and distribution (PMAD) prototype under a variety of thermal and electrical transient conditions.

\section{PMAD DESCRIPTION}

The PMAD system (Figure 1) is composed of a control computer and the PMAD cart that includes the components shown in the block diagram of Figure 2. The control computer is equipped with General Purpose Interface Bus (GPIB) and MIL-STD-1553 interfaces, which provide communication with instruments and modules within the PMAD cart. The series connected boost assembly (SCBA) and payload control unit (PCU) receive and execute commands and return telemetry information through the MIL-STD-1553 interface. The PMAD cart includes a remote computer that executes commands from the control computer including IV sweeps and data acquisition. The PMAD is connected in parallel with a seven-ohm resistor, which is in series with the diode string circuit. The seven ohm resistor ensures that a high voltage breakdown failure in the diodes cannot occur due to an open circuit. 


\section{DISCLAIMER}

This report was prepared as an account of work sponsored by an agency of the United States Government. Neither the United States Government nor any agency thereof, nor any of their employees, make any warranty, express or implied, or assumes any legal liability or responsibility for the accuracy, completeness, or usefuiness of any information, apparatus, product, or process disclosed, or represents that its use would not infringe privately owned rights. Reference herein to any specific commercial product, process, or service by trade name, trademark, manufacturer, or otherwise does not necessarily constitute or imply its endorsement, recommendation, or favoring by the United States Government or any agency thereof. The views and opinions of authors expressed herein do not necessarily state or reflect those of the United States Government or any agency thereof. 


\section{DISCLAIMER}

Portions of this document may be illegible in electronic image products. Images are produced from the best available original document. 


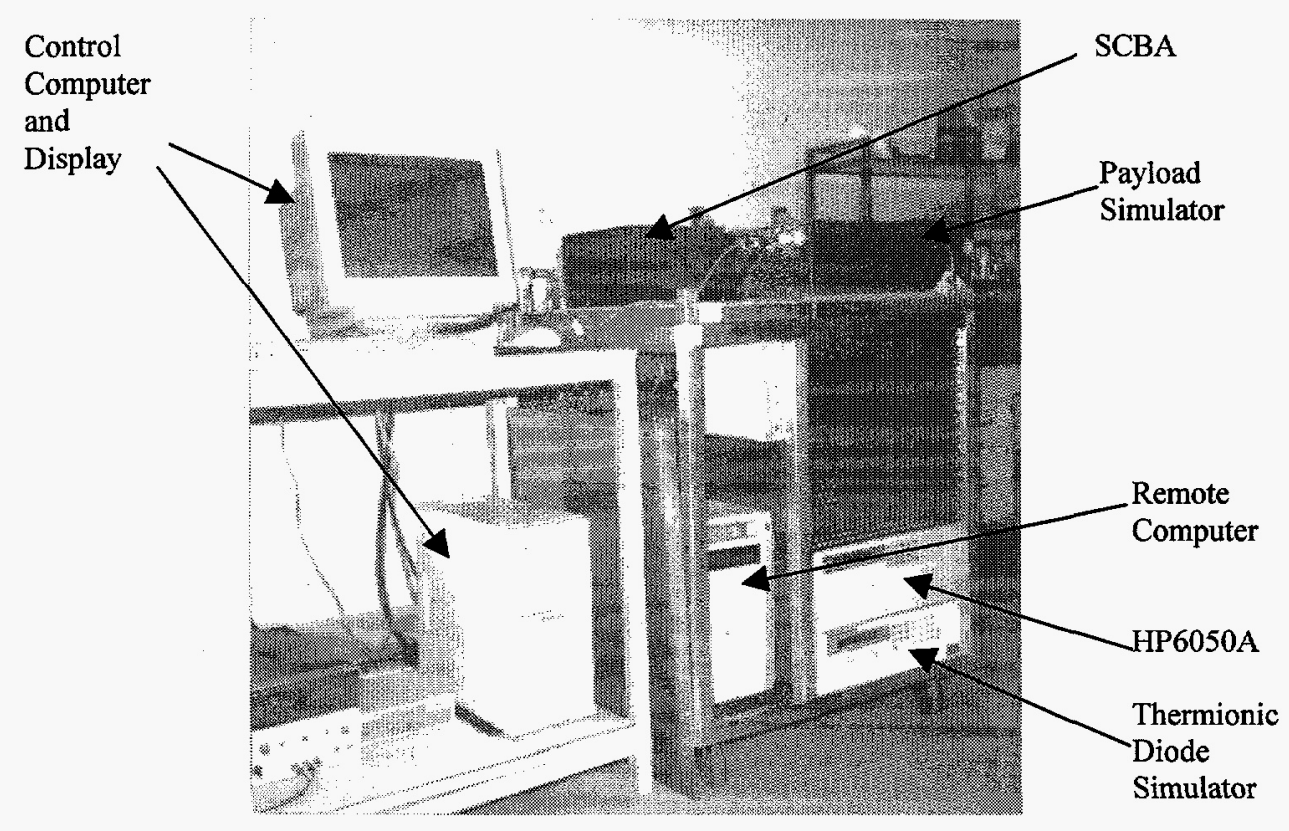

FIGURE 1. PMAD Cart and Operator Computer Console.

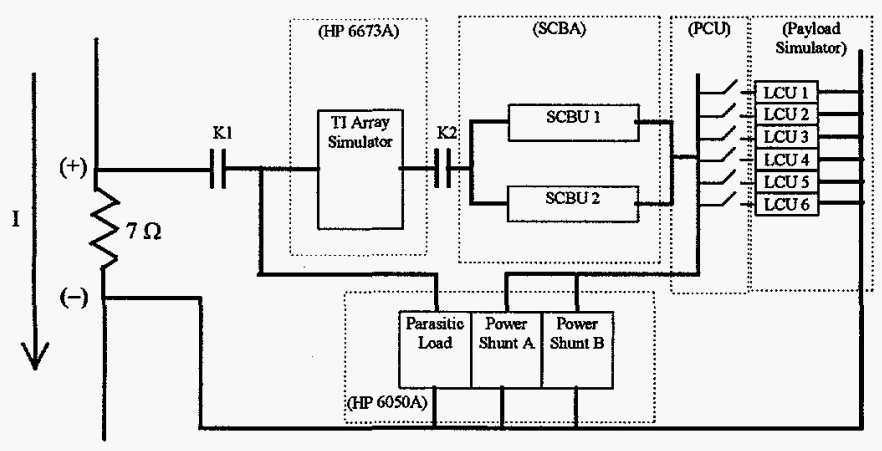

FIGURE 2. PMAD Block Schematic.

\section{PMAD DESIGN OBJECTIVES}

The PMAD's principal function aboard a spacecraft is to manage the power source so that the payloads are provided with regulated DC power in the event of radical changes in input power due to thermal transients (e.g., solar eclipse) and load variations. The heart of the ISUS PMAD is the SCBA, which uses commercial DC-DC converters in a series-boost configuration to provide voltage regulation of the thermionic converter power source. The NASA Lewis Research Center designed the SCBA to work with a 32-converter array although START-3 was only intended to test sixteen converters. A Thermionic Diode Simulator (TDSIM) is included with the PMAD system to double the output of the ISUS diode string to simulate the presence of the other sixteen diodes for PMAD testing.

The PMAD system is also designed to support testing activities with features that include a data acquisition system, IV sweep function, adjustable current and resistive loads and, as previously mentioned, the TDSIM, which can also be used to test PMAD operation without the thermionic converters. When the PMAD was first evaluated at NMERI, several additional features were identified that would greatly improve the flexibility of the system and the efficiency of performing repetitive operations such as determining the peak-power point for the array. The data acquisition 
system that was part of the PMAD system was originally programmed to collect data at one sample per second. The control computer software was modified to provide additional sampling rates from one sample per second to six samples per hour. The PMAD system automatically generates several data files, including the main data file, which records diode data as well as PMAD system data, and the operator log file that records the time and type of changes made to the PMAD system. Other data files are created for special operations such as IV sweeps and peak-power determination. As a backup procedure, the PMAD software was modified to automatically upload all the data files to the NMERI server.

The main diagnostic capability provided by the ISUS PMAD system is its ability to perform automated IV sweeps on the converter array. The PMAD performs IV sweeps by applying a stepped current load to the diode string while measuring the voltage of the array, as well as the voltage for each diode, at each current step. The Dynamic IV Sweep System (DIVSS), which is a separate system from the PMAD, provided another method of performing IV sweeps that superimposes an AC current on the steady-state DC operating point of the diodes. The string current is monitored while the individual diode voltage and array voltage is recorded by a digital oscilloscope. During START-3, IV sweeps were performed using both methods. Also of importance was the performance of the SCBR as a regulator of the converter array for specific payload requirements.

\section{The Series Connected Boost Regulator Technology}

The Series Connected Boost Regulator (SCBR) is a technology developed at the NASA Lewis Research Center that uses DC-DC converters in a unique topology to improve the power density and efficiency of boost regulators in power management systems. The SCBR uses an isolated DC-DC converter (step-down) and a bypass connection to reference the output voltage on top of the input voltage (see Figure 3).

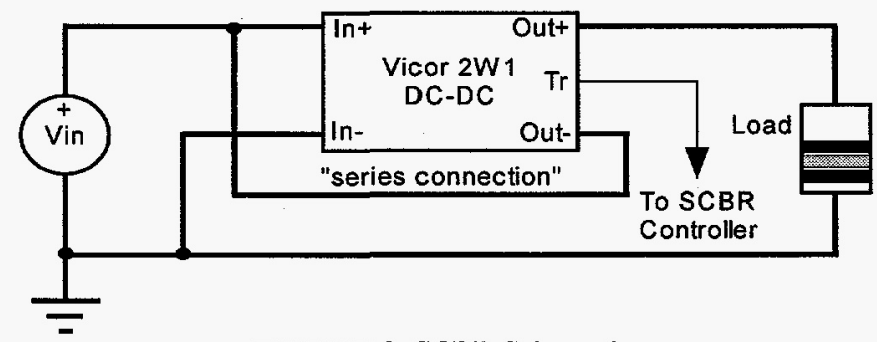

FIGURE 3. SCBR Schematic.

This configuration confers many benefits and few disadvantages. First, the power density of the converters is increased $100-400 \%$ since only the "boost" voltage is being processed by the DC-DC converters with the remaining power bypassed through the series connection. Second, efficiency is greatly increased to $94-98 \%$ for the same reason, even when using typical $\mathbf{8 0 - 8 5 \%}$ efficient commercial power supplies. Third, the fault tolerance of the system is enhanced since even a total failure of the DC-DC converter would still result in power delivery to the system. Finally, the SCBR can be easily configured in a number of grounding schemes, including positive ground for higher voltage systems.

The SCBR benefits of efficiency and power density come at a price. There are three limitations that a power system must meet to take full advantage of the SCBR topology: (1) The SCBR requires that the output voltage be greater than or equal to the input voltage at all times, (2) Galvanic isolation must not be required between the source and loads, and (3) The input voltage source must have a limited voltage range requiring only a small percentage $(<50 \%)$ of voltage boost. Several applications meet these requirements, including photovoltaic array regulation, battery output voltage regulation, and thermionic diode array regulation.

Typical applications of the SCBR require additional regulation circuitry to maintain output voltage and/or current regulation. A SCBR controller senses total output voltage and/or current and varies the boost voltage of the DC-DC converter to maintain regulation. The DC-DC converter voltage is controlled either through a provided trim pin or by using the remote sense input to make the converter operate at a lower output voltage. 


\section{ISUS SCBR Design Specifications}

The ISUS SCBR was designed to provide a regulated voltage to the spacecraft loads given an unregulated thermionic diode source. The expected diode source was a 32-diode string capable of producing $1200 \mathrm{~W}$ peak power. The expected range of the diode voltage was between 0.5 and $1 \mathrm{Vdc}$ per diode translating to an operational string voltage range of 16 to $32 \mathrm{Vdc}$. The Air Force desired a regulated output of $28 \pm 6 \mathrm{Vdc}$. The SCBR design resulted in a $30 \pm$ $2 \mathrm{Vdc}$ regulation range using a $12 \mathrm{~V}$ DC-DC converter (Figure 4). The power rating of $1200 \mathrm{~W}$ at a minimum voltage of around $25 \mathrm{Vdc}$ resulted in a maximum current of about $50 \mathrm{~A}$.

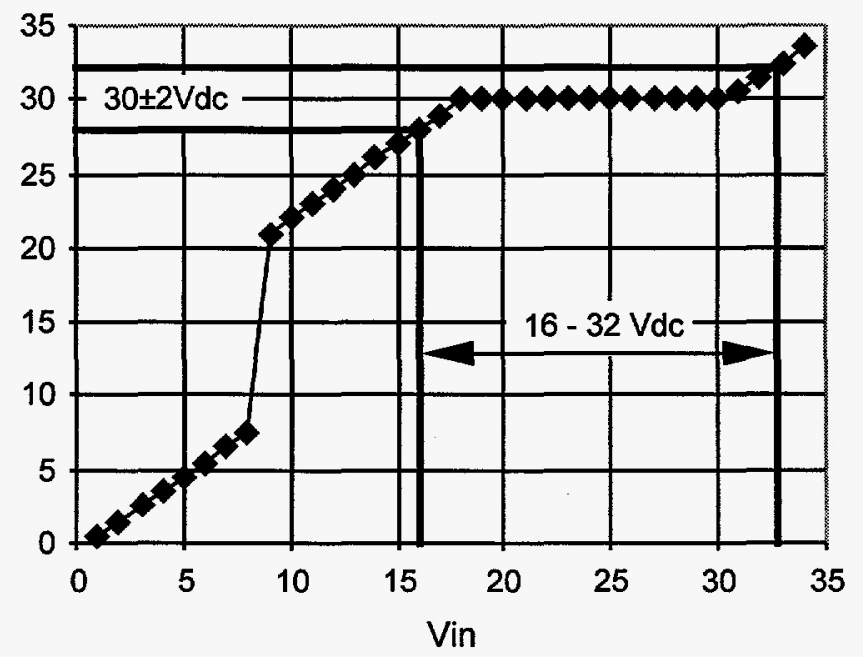

FIGURE 4. ISUS SCBR Operational Range.

The ISUS SCBR consisted of two Vicor 2W1-CV DC-DC converters $\left(V_{\text {in }}=16\right.$ to $36 \mathrm{Vdc}, \mathrm{V}_{\text {out }}=12 \mathrm{Vdc}, \mathrm{I}_{\text {out }}=12.5$ $A$ max., $P_{\text {out }}=150 \mathrm{~W}$ max.) in a master/slave parallel configuration for a maximum output current of $25 \mathrm{~A}$. The SCBR also included a power electronics board (filtering, fusing, and current sensing) and a controller board that contained the voltage and current controllers, paralleling circuits, on/off control, and telemetry conditioners. The SCBA (assembly) had two SCBRs connected in parallel to achieve the 50 A required. Two independent SCBRs were included to verify the modularity of the SCBR controllers and their ability to share current with other paralleled units. A block diagram of one SCBR is shown in Figure 5.

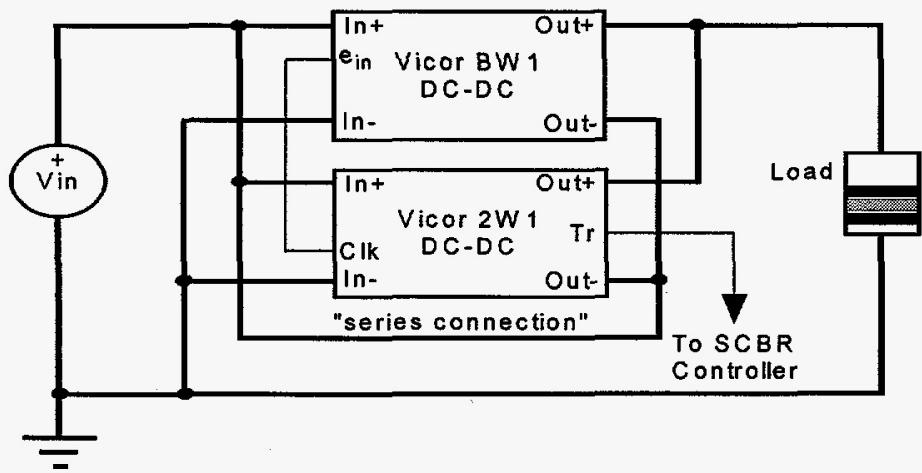

FIGURE 5. ISUS SCBR Block Diagram. 


\section{RESULTS}

During START-3, the IV sweep function of the PMAD worked very well for quick checks of diode condition since preparation time was minimal. The DIVSS has more flexibility and can drive the diode current to levels that exceed the PMAD ratings while the PMAD applies a variable current load and measures the resulting response. The IV characteristics shown in Figure 6 illustrate the difference in results from both systems where the DIVSS displays more of the characteristic and also provides the negative characteristic due to the negative half of the sine wave excitation.

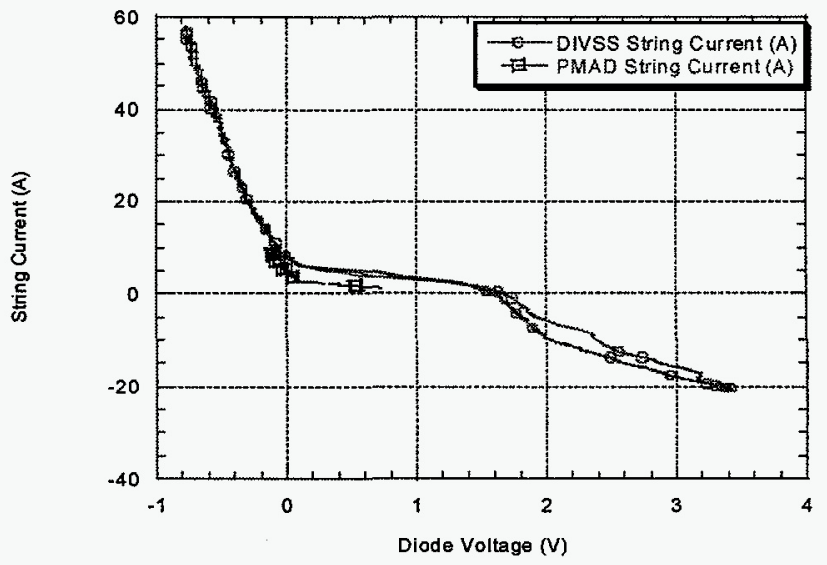

FIGURE 6. Comparison of IV Sweeps Performed by PMAD and DIVSS.

The operation of the DIVSS introduced several problems for the main data acquisition system and the PMAD. The magnitude of the signal from the DIVSS is sufficient at times to saturate the A-D converter on the data acquisition card. It was also discovered that the HP6050 electronic loads had a protection circuit that shunted current to the chassis ground if the applied voltage was found to be negative. The solution for the latter problem was to isolate all the HP6050 modules during DIVSS testing.

The PMAD was modified to accept bipolar input voltages so that it was possible to record early behavior of the diodes during warm-up. During START-3 several of the diodes developed negative voltages later in the test, so it was even more of an advantage to have these late effects correctly measured in the PMAD data file. The conversion to bipolar operation doubled the value of the least significant bit (LSB), which reduced the resolution by half, but because the voltages and currents of interest were much larger than the LSB, the loss in resolution had a negligible effect.

Figure 7 illustrates the operation of the PMAD SCBA at a constant diode emitter temperature of $1980 \mathrm{~K}$. The figure clearly shows a decrease in array voltage caused by an increase in current load. The SCBA was able to maintain the required output voltage despite a $50 \%$ decrease in the initial array voltage. To maintain constant output voltage, the SCBA requires more current from the array as the array voltage decreases, as shown in Figure 7. The efficiency of the SCBA is calculated based on the input voltage from the array and the boost voltage by the equation:

$$
e_{s c b u}=\frac{V_{i n}+V_{b o o s t}}{V_{i n}+\frac{V_{b o o s t}}{e_{d c}}},
$$

where $\boldsymbol{e}_{d c}$ is the efficiency of the DC-DC converter, which was assumed to be 0.85 (Button, 1997). In Figure 7 , 


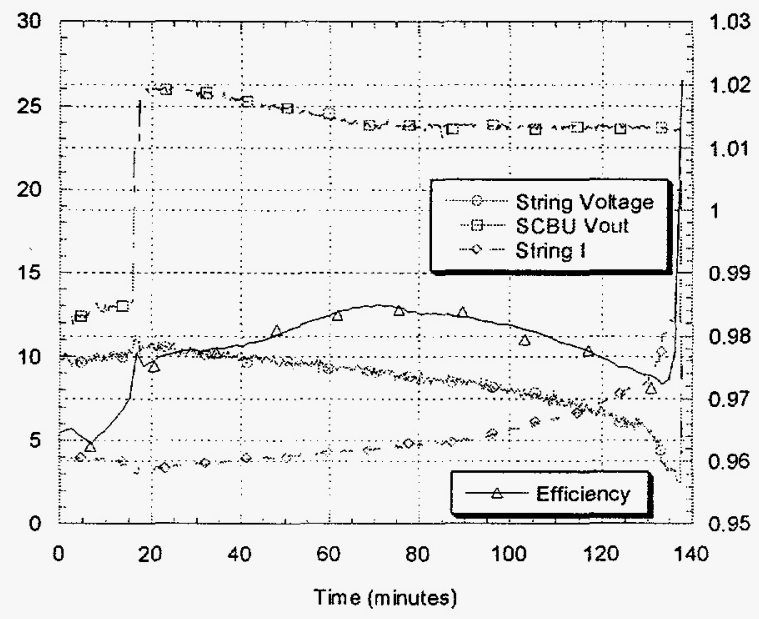

FIGURE 7. SCBA Regulation with Varying String Voltage.

the SCBA efficiency is observed to decrease with the array voltage due to an increase in $V_{\text {boost }}$ supplied by the SCBA to maintain output voltage.

\section{CONCLUSIONS}

The evaluation of the ISUS PMAD was one of the key secondary objectives of the START-3 test. Unfortunately, because the thermionic array performance was so far below the expectations, conditions wherein the PMAD could be operated within its design limits were very limited. For this reason, testing of the PMAD during thermal and electrical transients was not possible during the START-3 test. Follow-on tests are in progress that will characterize the PMAD's response to electrical transients and simulated array voltage variation for a range of SCBR setpoints. Despite the limitations imposed by the array performance, the PMAD was demonstrated to regulate the output of the thermionic diode array within the design requirements specified by the Air Force. Performance of the PMAD could be optimized for array voltages of less than 16 volts by a suitable selection of Vicor DC-DC converters.

\section{ACKNOWLEDGMENTS}

The work presented in this paper was conducted under the joint sponsorship of the U.S. Air Force Research Laboratory (AFRL) and the U.S. Defense Special Weapons Agency (DSWA). The authors would like to thank the members of the ISUS team at Lockheed Martin Electro-Optical Systems in Pomona, CA, NASA Lewis Research Center in Cleveland, OH, and the ISUS Program Office at Kirtland Air Force Base, Albuquerque, NM, for the exceptional support they provided during this test. Sandia is a multiprogram laboratory operated by Sandia Corporation, a Lockheed Martin Company, for the United States Department of Energy under Contract DE-AC0494AL85000.

\section{REFERENCES}

Button, R. M., "A Modular PMAD System for Small Spacecraft," Prepared for Space Technology and Applications International Forum-1997, .edited by M. S. El-Genk, New York, AIP Conference Proceedings \#387, 1997, pp. 263-268.

Kudija, C. T. and Frye, P. E., "Integrated Solar Upper Stage (ISUS) Engine Ground Demonstration (EGD)," in Space Technology and Applications International Forum-1998, edited by M. S. El-Genk, New York, AIP Conference Proceedings $\# 420$, 1998, pp. 348-353. 